\title{
Entrevista: Percurso Artístico do Angolano Eleutério Sanches
}

\author{
Por Carlos Alberto Alves ${ }^{1}$
}

Eleutério Sanches é poeta, artista plástico, músico e professor de Artes Plásticas. Nasceu em Luanda, Angola, em 1935. Antes de vir para Portugal estudar Belas Artes na Escola Superior de Belas Artes de Lisboa (ESBAL), em 1962, já se ocupava do desenho, música, pintura e teatro. Durante uma década foi monitor de pintura no departamento de ergoterapia do Hospital Júlio de Matos, em Lisboa. Os trabalhos artísticos do artista plástico Angolano foram expostos na sua terra natal, na Alemanha, na Áustria, nos EUA, em Macau, em Portugal e noutras partes do mundo. Esta entrevista foi realizada em Lisboa no mês de agosto de 1997.

\section{Como nasceu o seu gosto pela pintura e pelo desenho?}

O gosto pela pintura e pela linha nasceu desde criança. Gostava de desenhar na areia sem levantar a mão. Isto continua a ser legível nos trabalhos que faço onde o cromatismo está sempre presente. É uma constância na evolução do meu percurso onde há uma constante gráfica e cromática. O que me parece muito importante para quem cultiva as artes.

Alguns pintores não dão muita importância ao desenho. São opções. Eu, sou daqueles que, pelo contrário, dão realmente muita importância ao desenho. Neste aspeto é necessário passar pela iniciação académica correta, ainda que esse conhecimento ou aquisição possa ter uma via autodidata.

Porém, sem dúvida, a arte como exercício da liberdade é algo que permite sempre ao artista libertar-se de certos cânones, se for caso disso. O desenho é muito importante, porque é uma área de uma riqueza inesgotável. No grafismo livre, como daquele que parte do vocabulário geométrico, tenho desenvolvido uma gramática que é sempre suscetível de se multiplicar quer através das linguagens dos materiais quer através da investigação do próprio suporte ou espaço compositivo.

Em Luanda, tive contactos que funcionaram como estímulos, catalisadores que favoreceram o desenvolvimento do desenho. O contacto com o professor e escultor David Sousa, a quem eu mostrava de vez enquando, os meus desenhos, foi importante. Dele ouvia críticas construtivas que foram úteis para a minha carreira. $\mathrm{O}$ contacto também com alguns amigos e compatriotas, como o escritor Henrique Lopes Guerra (com o qual exercitei a observação direta), foi também muito útil.

1 Doutor em Identidades Práticas e Representações do Mundo Contemporâneo, especialidade em História Política e Relações Internacionais pela Universidade de Coimbra. É professor na ilha de S. Vicente, Mindelo, Cabo Verde, África Ocidental. Email: caa30@hotmail.com . 
Com ele procurei, através da observação atenta, a paisagem e a figura humana. Ainda hoje continuo com o gosto especial pela anatomia que me vem dessas primeiras experiências. A leitura do corpo humano apaixona-me. Em Luanda, entre outras, fiz uma experiência juntamente com o Rodolfo Teixeira e o Henrique que foi uma das minhas primeiras exposições.

\section{Sofreu algumas influências?}

A escola que tínhamos em Angola no meu tempo de estudante era empírica. Porém, havia troca de impressões com os que desejavam cultivar-se nessa área. Não havia uma Escola Superior de Belas Artes. Por isso, vim estudar para Lisboa. No contacto com a História da Arte, a certa altura, passámos a reconhecer grandes modelos que na cultura portuguesa e universal, nos influenciaram positivamente. Em Portugal, um dos casos que mais me impressionou foi o de Almada Negreiros. Era um homem profundamente ligado à linha e ao grafismo. Deixou uma obra muito singular com muita força e com muito gosto pela geometria e pelo número.

Para só falar de alguns impressionaram-me ainda outros trabalhos de artistas universais como: Miguel Ângelo, Leonardo Da Vinci, os artistas da escultura grega, cujas obras são de grande qualidade e elevação. É impossível qualquer estudioso não ficar impressionado com as suas obras e não colher deles ensinamentos que nos poderão ser sempre úteis, ainda que cada um tenha a sua maneira de criar e executar.

\section{Como caracteriza o seu percurso artístico?}

A primeira fase caracteriza-se por um desenvolvimento muito gráfico. Nesta fase, o grafismo desenvolveu-se a branco sob fundo negro. A motivação é essencialmente angolana com predominância da figura humana. Nessa altura o embondeiro já era uma das minhas paixões. Isto ligado à paisagem. É uma fase em que predomina o ambiente angolano suburbano e urbano.

A segunda fase caracteriza-se por um expressionismo interpretativo das figuras características de Angola, das características de África e de Luanda que é o meu berço. Esta fase é importante, na medida em que me deu alguns benefícios, em termos de estímulo, para depois me projetar na arte sem perder as características africanas.

Costumo disciplinar a minha obra. As minhas exposições costumam ter títulos que têm a ver com os ciclos que vou desenvolvendo. Há um ciclo a que eu chamei “Alquimia da Árvore”.

O embondeiro é uma árvore muito angolana, com uma robustez visível, com um apelo dramático enorme que transmite muito da nossa alma africana. É o vitalismo da África. Árvore 
mítica, com uma carga telúrica muito grande. Nesta fase, o embondeiro começa a ser tratado graficamente para depois evoluir para um cromatismo sóbrio.

Ao observarmos o ciclo evolutivo do embondeiro, constatámos que há um tratamento morfológico gráfico característico. Este, mais tarde, estará ligado ao cromatismo onde há um tratamento técnico muito rigoroso, em termos cromáticos resultado de uma alquimia muito morosa que só é possível fazer no tempo sobre posições várias. Assim, apetece, realmente, comparar a própria árvore com o ser eleito. A árvore nasce, cresce, dá flores e frutos. É todo este processo que é comparável àquilo que eu chamo "Alquimia da Árvore".

A minha experiência no Hospital Júlio de Matos teve um componente profundamente didática. Qualquer experiência pode ser didática. Tudo é aprendizagem, e ali aprendi bastante na medida em que tive um contacto com pessoas cujos problemas eram fundamentalmente de foro psíquico. A ergoterapia tem a função de ocupar as pessoas com problemas psíquicos, para assim se libertarem em tarefas que as possam ajudar a resolver os seus conflitos íntimos. Foi uma experiência importante. Lidei com registos vastíssimos de casos diferentes em que aprendi imenso. As coisas existem na nossa consciência em termos de arte. A partir daí, fiquei muito interessado pela pintura psicopatológica. Alguns quadros clínicos, que cheguei a conhecer e que me impressionaram pelos aspetos relativos aos esquizofrénicos, por exemplo. Verifica-se uma arte de grande riqueza e exuberância. Há fases de grande fecundidade, em termos produtivos, alternadas com fases de depressão. São aspetos que me tornaram ainda mais humano e me aproximaram do sofrimento dos outros. Assim, passei a compreender melhor toda a humanidade que nos envolve e de que fazemos parte.

\section{Que balanço faz destes anos de trabalho?}

O processo criador é complexo e difícil de avaliar. Tenho tentado disciplinar a minha obra por ciclos ou fases, linguagens e temas. As coisas acabam por se interpenetrar, embora possamos diferenciar os diversos ciclos que são definíveis e unidos uns aos outros.

$\mathrm{O}$ ato criador é múltiplo e busca a unidade. É muito difícil, à margem deste processo, que é dinâmico, falar dele próprio, ainda que seja preciso e importante fazê-lo também como exercício de introspeção. De facto, o meu processo é profundamente dinâmico, e hoje cada vez mais gosto de me socorrer de todos os instrumentos de estudo sem preconceito, ainda que tenha objetivos concretos a atingir.

Aquilo que há de transcendente no artista, ou seja, aquilo que é a sua própria mensagem 
deve ser revelado. Isto permitirá aos outros uma leitura artística global. Se este aspeto for legível poder-se-á colher, enfim, uma universalidade de sentimentos, uma pedagogia positiva para evolução desta humanidade cheia de inquietações, sofrimentos e problemas em coexistência realmente dramática. A arte tem uma dimensão terapêutica que me parece muito importante. Pessoalmente, ocupo-me disso.

\section{Na sua arte busca elementos tradicionais africanos?}

A arte tradicional africana é matriz da arte do mundo.

Para nós, que nascemos em África, é natural que não nos afastamos mas procuramos cada vez mais penetrar nela. Por exemplo, a arte tchokwe, que é rica com as suas mitografias, transmitenos um grande peso simbólico. No seu tratamento morfológico encontramos uma grande carga mítica, que é de uma execução elaborada. Isto apaixonou-me.

É a partir da matriz africana que eu parto para o universal. Pode-se ser africano, sendo também profundamente universal ao mesmo tempo. Não vejo nenhuma incompatibilidade nisso.

$\mathrm{Na}$ música tive várias influências. Em Luanda, havia uma música de matriz urbana e suburbana. Não posso deixar de falar de Liceu Vieira Dias (Carlos Aniceto Vieira Dias) ${ }^{2}$, que criou um suporte rítmico, e que outros - muito poucos - infelizmente terão ficado com essa herança cultural. Há, de facto, alguns músicos angolanos que guardam essa matriz. Ainda bem. Hoje sinto que a nossa música precisa de retomar essas raízes, realmente importantes para (re) construir a autenticidade da música que é a nossa. Estou a falar, em termos urbanos e suburbanos, de uma música que tem a ver com a vivência da cidade e do campo.

Já não falo da música étnica, própria dos povos de Angola. Houve algumas recolhas feitas pela Companhia de Diamantes de Angola muito importantes.

Porém, Liceu é uma referência que continua a ser muito interpretada. Seria muito útil que os compositores e os músicos atuais retomassem, com humildade, esse património onde ainda haverá certamente muito que aprender.

\section{Que recordações guarda do convívio com Liceu Vieira Dias?}

Convivi com Liceu Vieira Dias. Assisti a ensaios do "Ngola Ritmos" com todos os elementos do grupo. A convivência com eles foi muito agradável. O Liceu expressava-se com muita

2 Um dos fundadores do grupo musical Ngola Ritmos que teve um papel crucial na divulgação da música angolana dos anos 40 e 50 do século XX. Esteve preso por razões políticas no campo de concentração do Tarrafal em Cabo Verde. 
coerência e tinha as suas convicções próprias. Era uma pessoa que defendeu sempre a harmonia. Não só a harmonia musical, mas também entre todas as pessoas. Portanto, quando falo dele faço-o com admiração e afeto. Todas as recordações que tenho dele são as de um ser hospitaleiro, bom, simples e sem nada de artificial.

\section{Qual foi a sua experiência no teatro?}

Fiz teatro radiofónico.

No grupo dos "Jograis de Angola" aprendemos a dizer poesia. Tivemos um jornalista, que era cantor lírico, que nos ensinou a pegar num poema e a desmontá-lo, estudá-lo, adaptá-lo a uma interpretação de jogral com solistas e coros. Esta aprendizagem deu-nos bastante treino em termos do conhecimento do sentimento do ritmo, da dicção e do saborear das palavras ensinadas por Sousa e Costa. Na sua ausência, continuámos e conseguimos fazer recitais que ficaram na memória. Declamámos muitos poetas proibidos na altura. Tivemos alguns incómodos. Não obstante, conseguimos ter um percurso não muito longo mas significativo em termos de divulgação da poesia.

\section{Como artista, acredita na capacidade de criar traços culturais que permitam analisar e} explicar as diferenças de cada povo?

Acredito. As diferenças existem morfologicamente, filosoficamente e culturalmente. Nós temos o dever de conhecer, em primeiro lugar, as diferenças o que não é fácil. Depois de conhecêlas, na profundidade, é preciso um estudo continuado para ver aquilo que é comum na humanidade.

Há muito mais coisas para unir as pessoas do que aquelas que as separam. Isso é belo. É um dos grandes atributos da beleza. Isso deve dar-nos a capacidade de amar o outro e (re) conhecê-lo. Temos que entender as diferenças com muita generosidade, e não com paternalismo. Só assim podemos acentuar uma permuta saudável com todas as culturas, conhecimentos, religiões, filosofias, políticas, etc.. Tudo é património da humanidade, onde vivemos.

Até que ponto o artista, com o pincel e a paleta, pode contribuir para a construção de uma sociedade livre e justa?

$\mathrm{O}$ artista pode, se for culturalmente honesto. Quando ele cria, está a fazer um exercício de liberdade. Cada artista tem capacidade para desenvolver a sua arte até à exaustão. Cada artista não se esgotará em si mesmo. Essa atitude, se for transportada e se projetar com elevação naquilo que 
faz, penso que vai refletir-se na humanidade.

A arte é uma área complexa, variada e suscetível de conter coisas diferentes e tão antagónicas e complexas que o espírito integrador do artista sabe harmonizar. Por isso, há muitos riscos. Assim como pode refletir uma arte terapêutica que faz bem à humanidade, pode também refletir aspetos menos saudáveis, que é necessário denunciar.

Não aplaudo os aspetos gratuitos, que só têm finalidade de ostentação, isso é pobre. Não serve para nada e não tem dimensão ética. Por isso, cria confusão, sobretudo em muita gente que não tem capacidade de avaliação conveniente, quando a arte é complexa.

Acho que os artistas, os pintores de qualquer manifestação artística, têm grande responsabilidade, porque a arte é para ficar. Por isso, ela deve ser o melhor de nós próprios. Ainda que, no melhor de nós próprios, seja difícil separar o negativo, penso que deve ser feito de tal forma que se deixa aos presentes e futuros a capacidade de optarem.

\section{Como conjuga a escrita, a pintura e a música?}

Não faço uma gestão matemática do tempo.

O processo criador não obedece a nenhuma rigidez cronológica. Falta-me sempre tempo. É a matéria-prima mais cara. É o mal da nossa época. Nós estamos completamente atingidos por demasiadas coisas que passam no mundo, todos os dias. Algumas são boas e outras más, infelizmente. Isto afeta-nos como seres sensíveis que somos. E, naturalmente, reflete-se no nosso trabalho. Pode ser motivação e estímulo para o artista.

\section{Conte-nos um pouco a experiência de professor de Artes e de músico?}

Não há professores de arte. Há pessoas capazes de iniciar os outros em arte. Estou a ensinar áreas de Artes Plásticas no ensino secundário, que passam por um diagnóstico de sensibilidade, vocação, capacidade de trabalho e gosto. Depois temos que nos debruçar caso a caso e ver o que cada aluno precisa.

Não podemos usar um método pedagógico igual para todos. Temos que nos debruçar sobre cada caso com empenho e generosidade. Por isso, é preciso ter amor pelas pessoas. Essa tem sido a minha postura, correndo riscos. Nós corremos riscos e gostamos que os alunos corram também. Por exemplo, no ato de começar a desenhar partindo de um modelo concreto, eles estão a pensar. E eu digo para não ficarem a pensar sem fazer. Isto vai dar-lhes uma capacidade de libertação que eles precisam: desenvolver os aspetos gestuais do fazer. 
No fazer correm-se riscos. Isto é importante, pedagogicamente, para quem inicia os outros na arte. $\mathrm{O}$ nosso debruçar constante e a nossa atenção é crucial.

Como músico, sinto-me e sou um trovador. Foi sempre o meu género e o que eu fiz. Em África, há um aspeto trovadoresco que hoje não é muito visível, infelizmente. Ouve-se, nos nossos dias, muita música comercial.

A canção é um casamento de poesia com música. Faço questão de cuidar, de modo especial, os textos que costumo musicar. A poesia pode ser lida, cantada e saboreada. Deve-se partir da poesia para a música. Temos de partir sempre da música para a poesia. Isto é importante para celebrar o casamento que gera uma canção. 